\title{
Infertility and the excruciating pursuit of motherhood
}

URMILA G

\section{Rohini S Rajagopal, What's a Lemon Squeezer Doing in My Vagina? Haryana: Penguin Random House; 2021. Rs. 399, 288pgs, ISBN: 9780143452003}

What's a Lemon Squeezer Doing in My Vagina? is a memoir of Rohini S Rajagopal's excruciating five-year long fight with infertility and her journey to motherhood. After several failed attempts at natural conception and many negative home pregnancy tests, the author and her husband Ranjith visit a fertility centre in Bangalore. Rajagopal delivers a graphic description of the physical and emotional unpleasantness of her infertility treatment and also gives a vivid account of her experiences with the assisted reproductive technologies (ARTs) such as the intrauterine insemination (IUIs), in-vitro fertilisation (IVF) and intracytoplasmic sperm injection (ICSI). Intrauterine Insemination (IUI) is facilitated by directly injecting a man's sperm into the woman's uterus around the time the eggs emerge from the ovaries. In in-vitro fertilisation (IVF), the eggs are retrieved from the female body and carefully fertilised in a laboratory using sperm to create an embryo which will then be transferred to the uterus. In the more advanced intracytoplasmic sperm injection (ICSI) a single selected sperm is directly injected into the retrieved egg, leading to fertilisation. And as with IVF, the fertilised embryo is then transferred to the woman's uterus. The "lemon squeezer" in the title of the memoir represents the arduous path Rohini Rajagopal had to take; the invasion of her body by medical tools, fertility drugs, hormonal treatments, medical tests, and minor surgeries, which she endured over the years to successfully conceive. These procedures lead to unavoidable anxieties concerning their outcome, where Ranjith, her husband, becomes a mere spectator to her

Author: Urmila G (urmila.g@learner.manipal.edu), PhD Scholar, Manipal Centre for Humanities, Manipal Academy of Higher Education (MAHE), Alevoor Road, Manipal, Karnataka, 576104 INDIA

To cite: Urmila G. Infertility and the excruciating pursuit of motherhood. Indian J Med Ethics. Published online on July 29, 2021. DOI: 10.20529/IJME. 2021.057

Manuscript Editor: Sanjay A Pai

(c) Indian Journal of Medical Ethics 2021 journey, unable to help with the medical functionalities of the treatment. He experiences and manages his own anxieties separately to Rajagopal.

In addition to the medical and biological aspects, the memoir reveals the intrinsic social and cultural factors associated with infertility. The author also delves into the guilt and shame she had to bear after failing to conceive "naturally". Through the author's life we see how the biomedical correlation of ageing and female reproduction affects the quality of a married woman's social life. She fears that her fertility and reproductive capabilities will become the subject of conversations at family gatherings, and that she will face unanswerable frustrating questions from relatives. The phrase, "ticking of the biological clock" would be all too familiar to women of reproductive age in a country like India. Similarly relatable would be the insecurity that Rajagopal experiences, seeing other women effortlessly break into the "exclusive club" of pregnancy.

Crucially, the final chapter of What's a Lemon Squeezer Doing in My Vagina? is titled "Why Want Children?" This is a question some of the readers might also ask after going through the intensity of Rajagopal's medical and financial hardships before she can conceive. Indeed, the author does not have a clear answer to it. However, she does not claim that being a mother or experiencing all the "gore and grime" of infertility is the single greatest achievement of her life. In fact, she admits to having bought into the various prevalent myths about the significance of motherhood and she addresses the effect it has had on her. This is a major strength of this account. These insights and the final resolution of her initial ethical conundrum of acknowledging her infertility makes Rajagopal's memoir a significant addition to the field of medical humanities.

In India, where the value of an individual is often assessed by the conservative public through his/her ability to procreate, diagnosing infertility brings forth a barrage of problems. The World Health Organisation estimates that around 48 million couples and 186 million individuals globally suffer from infertility (1). In India alone, the prevalence of primary infertility ranges between $3.9 \%$ and $16.8 \%$ (2). In such cases, ARTs play a significant role. Rajagopal's story has much relevance in today's world where more women who want children are seeking help from fertility clinics that offer them a ray of hope. However, an undeniable fact is the tediousness of such an endeavour and the impact it has over the physical 
and emotional wellbeing of the woman, which this memoir has meticulously portrayed. While her story has a happy ending, she reminds the readers from the outset that it is also a chronicle of multiple failures and several miscarriages (which she mentions as "deaths"). As the author herself states, What's a Lemon Squeezer Doing in My Vagina?, is as much a story about the "transformative powers of reproductive science" as it is about "the ugliness of infertility treatment".
References

1. World Health Organization. Infertility. Geneva; WHO;2020 Sep 14 [cited 2021 Jul 29]. Available from: https://www.who.int/news-room/ fact-sheets/detail/infertility.

2. Katole A, Saoji AV. Prevalence of Primary Infertility and its Associated Risk Factors in Urban Population of Central India: A CommunityBased Cross-Sectional Study. 2019 Oct-Dec [cited 2021 Jul 29];44 (4). 337-41. Available from: https://www.ncbi.nlm.nih.gov/pmc/articles/ PMC6881900/ 